\title{
PENGELOLAAN SUMBER DAYA MANUSIA WIDYAPRADA DI LEMBAGA PENJAMINAN MUTU PENDIDIKAN KALIMANTAN BARAT
}

\author{
Endang Sukowati, Wahyudi, H.M. Chiar \\ Program Studi Magister Administrasi Pendidikan FKIP Universitas Tanjungpura Pontianak \\ Email: endangsukowati02@gmail.com
}

\begin{abstract}
The purpose of this research in general is to obtain accurate information about the management of widyaprada human resources in LPMP West Kalimantan. This study uses a descriptive method with a qualitative approach. Data collection techniques using interviews, observation and documentation. The results of the study are 1) that the Widyaprada human resource planning at LPMP West Kalimantan refers to and is guided by central policies. 2) the implementation of Widyaprada human resource management at LPMP West Kalimantan has been running smoothly following the applicable regulations. 3) evaluation of Widyaprada's human resource management is carried out and received at the beginning of each year (evaluation in 2020 is carried out in early $2021)$ in the form of SKP. 4) The obstacle in managing Widyaprada's human resources at LPMP West Kalimantan is if there is a sudden change in policies and rules while work activities are in progress. 5) Efforts to overcome obstacles in managing Widyaprada's human resources at LPMP West Kalimantan are by working solidly as a team, conducting internal analysis, coordinating and communicating with the central party.
\end{abstract}

\section{Keyword: Management, Human Resources, Widyaprada.}

\section{PENDAHULUAN}

Sumber daya organisasi terdiri dari sumber daya manusia dan sumber daya alam. Dari kedua sumber daya tersebut, sumber daya manusia menjadi penentu keberhasilan dalam mencapai tujuan organisasi/institusi. Garaika (2020, p.3) mengungkapkan bahwa, "SDM meliputi keseluruhan orang yang ada dalam organisasi dan terlibat dalam operasional bisnis perusahaan, mulai tingkat terbawah hingga ke posisi direktur utama". Sedangkan Priyono d., \& Marnis (2008, p.15) mengungkapkan bahwa, "Sumber daya manusia adalah kemampuan terpadu dari daya pikir dan daya fisik yang dimiliki individu". Keberadaan sumber daya manusia dalam suatu organisasi memiliki peran sentral dan sangat penting bagi tercapainya tujuan organisasi.

Dikatakan merupakan sektor sentral dan penting dalam mencapai tujuan organisasi atau institusi, karena pergerakan suatu lembaga secara dinamis, sangat tergantung dari kompetensi, kualitas dan komitmen anggota organisasi. Torres-Coronas d., \& Arias-Oliva (2005, p.5) mengungkapkan bahwa, "The company should promote individual autonomy and personal accountability at all levels of the organization through the process of work design, to make the company more flexible to change". Artinya, perusahaan harus mempromosikan otonomi individu dan kemampuan pribadi di semua tingkatan organisasi melalui proses desain kerja, untuk membuat perusahaan lebih fleksibel untuk berubah".

Belakangan ini dalam kehidupan masyarakat terdapat banyak perubahan yang diakibatkan oleh kemajuan. Adapun kemajuan yang dicapai tersebut adalah berasal dari proses pembangunan sebelumnya dan tentunya kemajuan yang pesat dalam ilmu pengetahuan dan teknologi secara global. Tidak hanya 
secara fisik, mental dan pemikiran masyarakat juga ikut mengalami perubahan sekarang ini yaitu terjadinya perubahan pola pikir masyarakat ke arah yang semakin kritis. Hal ini sangat dimungkinkan, karena semakin hari masyarakat menjadi semakin cerdas dan mulai memahami hak dan kewajibannya sebagai warga negara. Kondisi masyarakat yang seperti itu memerlukan pemerintahan yang mampu memenuhi segala macam tuntutan kebutuhan pada setiap aspek kehidupan mereka, terutama dalam hal mendapatkan pelayanan yang baik dari pemerintah.

LPMP Provinsi Kalimantan Barat memiliki salah satu misi yang menunjukkan komitmen terhadap pelayanan publik yang prima, sebagaimana dilansir dari laman lpmpkalbar.id yaitu, "Meningkatkan kapasitas lembaga dalam memberikan layanan penjaminan mutu pendidikan". Salah satu target yang ingin dicapai LPMP Provinsi Kalimantan Barat berkenaan dengan pelaksanaan reformasi birokrasi sebagaimana dilansir dari lpmpkalbar.id adalah, "Meningkatnya mutu pelayanan publik (lebih cepat, lebih murah, lebih aman, dan lebih mudah dijangkau)". Adapun tujuan utama dari penjaminan mutu pendidikan secara umum sebagaimana dikemukakan oleh Sukardjo d., \& Ukim Komarudin (2009, p.92) yaitu, "Dengan penjaminan mutu ini, diharapkan tumbuh budaya mutu mulai dari; bagaimana menetapkan standar, melaksanakan standar, mengevaluasi pelaksanaan standar, dan secara berkelanjutan berupaya meningkatkan standar (Continuous Quality Improvement)".

LPMP Kalimantan Barat merupakan salah satu unit pelaksana teknis (UPT) Kementerian Pendidikan dan Kebudayaan yang ada di Provinsi Kalimantan Barat yang telah banyak berprestasi di berbagai bidang pada skala nasional, diantaranya adalah pernah mendapatkan predikat e-kehadiran terbaik dari 34 Provinsi di Indonesia pada tahun 2018. Kemudian pada tahun 2019 berhasil mendapatkan predikat Zona Integritas Wilayah Bebas dari Korupsi (ZI-
WBK) dari Kementerian Pendayagunaan Aparatur Negara dan Reformasik Birokrasi (Menpan-RB) dan pada tahun 2020 LPMP Kalimantan Barat berhasil mendapatkan predikat terbaik ke-2 di bidang Sistem Akuntabilitas Kinerja Instansi Pemerintah (SAKIP) dari Kementerian Pendidikan dan Kebudayaan. Prestasi-prestasi tersebut di atas menunjukkan bahwa LPMP Kalimantan Barat berhasil mengelola sumber daya manusia internalnya dengan baik.

Dalam hal penjaminan mutu pendidikan LPMP Kalimantan Barat merupakan intansi Pembina dari 6.234 satuan pendidikan pada jenjang pendidikan dasar dan pendidikan menengah yang tersebut di 14 kabupaten/kota di Provinsi Kalimantan Barat. Pada tahun 2021 sasaran program fasilitasi dan pembinaan lembaga satuan pendidikan dalam rangka layanan penjaminan mutu pendidikan dasar dan menengah berjumlah 3.827 lembaga satuan pendidikan di 14 Kabupaten/Kota di Provinsi Kalimantan Barat dengan tenaga fujngsional Widyaprada yang berjumlah 8 orang tentu ini merupakan pekerjaan yang cukup berat.

Sesuai dengan peta jabatan yang ada jumlah tenaga fungsional Widyaprada masih belum tercukupi. Pada jabatan Widyaprada ahli pertama tenaga yang dibutuhkan adalah 17 orang namun saat ini belum ada yang mengisi jabatan tersebut. Pada jabatan Widyaprada ahli muda, tenaga yang dibutuhkan adalah 10 orang akan tetapi baru terisi 1 orang dan pada jabatan Widyaprada ahli madya yang dibutuhkan adalah 6 orang dan yang ada sekarang 6 orang. Dengan demikian, dapat dilihat bahwa tenaga Widyaprada di LPMP Kalimantan Barat masih kurang, sehingga untuk mendukung tugas-tugas Widyaprada ada sejumlah staf yang diberikan tugas tambahan untuk membantu tugas-tugas Widyaprada.

Permasalahan dalam pengelolaan sumber daya manusia di LPMP Kalimantan Barat adalah kemampuan individu yang tidak sama, jumlah personil yang terbatas dengan kompleksitas pekerjaan yang ada, keterbatasan anggaran, keterbatasan sarana dan prasarana, serta luasnya wilayah kerja 
dengan berbagai latar belakang sosial budaya yang berbeda-beda, sehingga perlu pengelolaan sumber daya manusia yang tepat agar tujuan organisasi dapat tercapai secara maksimal.

Berdasarkan latar belakang tersebut di atas, maka peneliti telah melakukan penelitian mengenai Pengelolaan Sumber Daya Manusia Widyaprada di Lembaga Penjaminan Mutu Pendidikan Kalimantan Barat.

\section{METODE PENELITIAN}

Penelitian ini bertujuan untuk mendeskripaikan secara lebih komprehensif tentang pengelolaan sumber daya manusia Widyaprada di LPMP Kalimantan Barat, maka pendekatan yang sesuai adalah kualitatif.

Pendekatan penelitian kualitatif merupakan salah satu jenis penelitian yang spesifikasinya adalah sistematis, terencana, dan terstruktur dengan jelas sejak awal hingga pembuatan desain penelitiannya. Definisi lain menyebutkan penelitian kualitatif adalah penelitian yang banyak menuntut deskripsi dalam bentuk kalimat narasi, dalam penafsiran terhadap data tersebut, serta penampilan dari hasilnya. Demikian pula pada tahap kesimpulan penelitian merupakan kesimpulan dari deskripsi terhadap data yang diperoleh.

Dalam penelitian ini, jenis penelitian yang digunakan adalah studi kasus. Stake dalam (Emzir, 2009, p.23) memaparkan bahwa: "Studi kasus, dalam penelitian ini peneliti menelusuri secara mendalam (indepth) program, kejadian, aktivitas, proses dari satu atau lebih individu. Kasus-kasus dibatasi oleh waktu dan aktivitas, dan peneliti mengumpulkan informasi detail menggunakan variasi prosedur pengumpulan data melalui periode waktu yang cukup".

Adapun yang menjadi dasar penerapan jenis penelitian ini adalah karena konteks atau isi penelitian bersifat natural, atau memaparkan temuan penelitian dengan apa adanya tanpa rekayasa, jenis data yang dibutuhkan bersifat kualitatif dan terfokus. Cara atau teknik yang digunakan bersifat induktif, artinya memaparkan temuan berdasarkan hasil wawancara, observasi dan analisis dokumentasi untuk kemudian disimpulkan. Dalam penarikan kesimpulan, peneliti sebelumnya akan menyepakati terlebih dahulu hasil-hasil temuan dengan narasumber. Selain itu, sumber data penelitian bersifat purposive bukan acak, yaitu telah ditentukan kriteria-kriteria subjek penelitian yang menjadi sumber data penelitian.

Data yang diperoleh melalui kegiatan penelitian merupakan faktor yang sangat penting untuk memecahkan masalah penelitian. Oleh karena itu, data yang diperoleh haruslah data yang akurat dan dapat dipertanggung jawabkan secara ilmiah. Scott W. Vanderstoep d., \& Deirdre D. Johnston (2009, p.224) menyebutkan: "A qualitative study involves the analysis of language and nonverbals, in observations and interviews, the analysis of current and historical documents, and even the analysis of oneself'. Artinya, studi kualitatif melibatkan analisis bahasa dan nonverbal, pengamatan dan wawancara, analisis dokumen saat ini dan terdahulu dan bahkan analisis diri sendiri. Sehubungan dengan itu, diperlukan penggunaan teknik dan alat pengumpul data yang tepat, ada beberapa teknik yang digunakan dalam suatu penelitian dan setiap teknik yang satu dengan teknik yang lain sangat berbeda.

Berkaitan dengan teknik pengumpul data, Sugiyono (2018, p.105) mengungkapkan empat (4) teknik pengumpul data dalam penelitian kualitatif, yaitu: "Observasi (pengamatan), interview (wawancara), kuesioner (angket), dokumentasi dan gabungan keempatnya".

Data yang diperoleh dari hasil wawancara, hasil observasi dan analisis dokumen dan dimaknai secara kualitatif. Dalam proses analisis data kualitatif Bogdan (dalam Sugiyono, 2018, p.130) menyatakan bahwa: "Data analysis is the process of systematically searching and arranging the interview transcripts, fieldnotes, and other materials that you accumulate to increase your own understanding of them and to 
enable you to present what you have discovered to others". Artinya bahwa analisis data adalah proses mencari dan menyusun secara sistematis data yang diperoleh dari hasil wawancara, catatan lapangan, dan bahan-bahan lain, sehingga dapat mudah dipahami dan temuannya dapat diinformasikan kepada orang lain.

Selanjutnya Susan Stainback (dalam Sugiyono, 2018, p.130) mengemukakan bahwa: "Data analysis is critical to qualitative research process. It is to recognition, study, and understanding of interrelationship anc concept in your data that hypotheses and assertions can be developed and evaluatuted". Artinya, analisis data merupakan hal yang kritis dalam proses penelitian kualitatif. analisis digunakan untuk memahami hubungan dan konsep dalam data sehingga hipotesis dapat dikembangkan dan dievaluasi.

Pendapat lain dikemukakan oleh Spradley (dalam Sugiyono, 2018, p.131) yaitu: "Analysis of any kind involve a way of thinking. It refers to the systemathic examination of something to determine its partsm the relation among parts, and the relationship to the whole. Analysis is a search for patterns". Artinya, analisis dalam penelitian jenis apapun adalah merupakan cara berpikir. hal itu berkaitan dengan pengujian secara sistematis terhadap sesuatu untuk menentukan bagian, hubungan antar bagian dan hubungannya dengan keseluruhan. Analisis adalah untuk mencari pola.

Berdasarkan beberapa pendapat tersebut maka ditarik kesimpulan bahwa analisis data adalah proses mencari dan menyusun secara sistematis data yang diperoleh dari hasil wawancara, catatan lapangan dan dokumentasi dengan cara mengorganisasikan data ke dalam kategori, menjabarkan ke dalam unit-unit, melakukan sintesa, menyusun ke dalam pola, memilih mana yang penting dan akhirnya membuat suatu simpulan sehingga mudah dipahami oleh diri sendiri dan orang lain.

\section{HASIL PENELITIAN DAN PEMBAHASAN Hasil}

Hasil wawancara yang diperoleh mengenai perencanaan pengelolaan sumber daya manusia Widyaprada didukung dengan temuan analisis dokumen yang menunjukkan bahwa surat pengajuan kebutuhan formasi Widyaprada dan Surat Keputusan Kepala LPMP Kalimantan Barat tentang kebutuhan formasi Widyaprada tidak ada, karena jabatan Widyaprada yang ada saat ini adalah hasil dari proses inpasing bukan formasi. Surat pemberitahuan tentang pendaftaran dan seleksi formasi Widyaprada tidak ada, karena merupakan kewenangan Bagian Kepegawaian di Direktorat Jenderal Pendidikan Anak Usia Dini, Pendidikan Dasar dan Pendidikan Menegah di Jakarata. Data Widyaprada yang aktif saat ini ada. Data Widyaprada yang telah memasuki masa pensiun dapat dilihat dari data Widyaprada yang ada. Data perencanaan kebutuhan Widyaprada tidak ada, karena data tersebut masih di pusat belum di informasikan ke daerah. Data kekurangan jumlah tenaga Widyaprada ada, yaitu dari Peta Jabatan. Pengumuman tentang kebutuhan Widyaprada, penjelasan tentang jumlah kebutuhan Widyaprada dan lampiran tentang tata cara seleksi Widyaprada tidak ada, karena merupakan kewenangan Bagian Kepegawian di Direktorat Jenderal Pendidikan Anak Usia Dini, Pendidikan Dasar dan Pendidikan Menengah di Jakarta. Data Widyaprada yang berasal atau pindahan dari instansi lain belum ada, kemungkinan ada apabila ada satuan kerja lain yang digabung. Untuk data-data kegiatan-kegiatan pelatihan Widyaprada dipegang oleh masingmasing Widyaprada belum di buat data rekapnya, karena Widyaparada yang ada mengikuti kegiatan bimbingan teknis secara mandiri. Data mutasi atau promosi Widyaprada tidak ada. SK penempatan dan tugas Widyaprada ada.

Hasil wawancara yang diperoleh mengenai pelaksanaan pengelolaan SDM Widyaprada didukung dengan temuan hasil observasi yang menunjukkan bahwa belum 
ada dokumentasi pertemuan awal Widyaprada dengan pegawai-pegawai LPMP Kalimantan Barat, yang ada adalah dokumentasi pelantikan Widyaprada. Belum ada notulen rapat koordinasi awal kepala LPMP Kalimantan Barat dengan Widyaprada setelah pelantikan. Belum ada dokumentasi pertemuan koordinator Widyaprada dengan tenaga fungsional Widyaprada. Belum ada dokumentasi pertemuan Kasubbag Umum dengan Widyaprada. Belum ada aturan atau petunjuk teknis tentang besaran tunjangan fungsional Widyaprada. Sudah ada aturan atau petunjuk teknis tentang penyesuaian tunjangan Widyaprada. Terdapat dokumendokumen tentang tugas Widyaprada di lapangan. SPJ perjalanan dinas Widyaprada belum ada, yang ada adalah Surat Tugas. SK Kenaikan Pangkat Widyaprada belum ada, yang ada adalah SK Pengangkatan Widyaprada (Pengangkatan Melalui Penyesuaian Nomenklatur dalam Jabatan Fungsional Widyaprada). Catatan perilaku Widyaprada belum ada (penilaian prilaku di lakukan pada awal tahun, untuk penilaian prilaku tahun sebelumnya). Terdapat absensi dan catatan kehadiran Widyaprada.

Hasil wawancara yang diperoleh mengenai evaluasi pengelolaan SDM Widyaprada didukung dengan temuan hasil observasi yang menunjukkan bahwa Hasil penilaian dalam SKP Widyaprada belum ada (akan diterima pada awal tahun). Catatan tentang kondisi personal Widyaprada di dalam SKP belum ada (akan diterima pada awal tahun). Terdapat rencana program kegiatan untuk pengembangan SDM Widyaprada.

Berdasarkan data yang diperoleh dari hasil wawancara dengan Kepala LPMP Kalimantan Barat pada tanggal 2 Juni 2021 dan Kasubbag Umum pada tanggal 4 Mei 2021, terdapat beberapa hal yang membuat pelaksanaan pengelolaan sumber daya manusia Widyaprada ini mengalami hambatan, yaitu:

a. Program dan anggaran terhambat karena terjadi perubahan peraturan secara mendadak. b. LPMP Kalimantan Barat berada pada masa transisi untuk menjadi Balai Besar Peningkatan Mutu Pendidikan, sehingga program-program yang dilaksanakan adalah program-program transisi, sehingga Widyaprada harus menganalisis dan menyesuaikannya dengan kondisi wilayah kerja.

c. Perubahan kebijakan berpengaruh pada program kegiatan.

Hasil wawancara yang dilakukan terhadap Kepala LPMP Kalimantan Barat pada tanggal 2 Juni 2021 dan Kasubbag Umum pada tanggal 4 Mei 2021 mengenai upaya untuk mengatasi hambatan yang dihadapi adalah dengan cara:

a. Menciptakan tim yang solid dan bekerjasama untuk menyikapi setiap perubahan peraturan yang terjadi.

b. Melakukan penyesuaian diri untuk menyikapi perubahan lingkungan.

c. Melakukan analisis SDM berdasarkan panduan dan arahan dari pusat (melalui kegiatan Bimtek yang diselenggaran pusat).

d. Analisis kebutuhan organisasi disusun oleh Kasubbag Umum dan tata laksana kepegawaian. Pihak pusat yang mengundang untuk berkoordinasi.

e. Seminggu sekali dilakukan pertemuan secara daring oleh Unit utama untuk Kepala-Kepala LPMP se-Indonesia dipimpin langsung oleh Sekretaris Direktorat Jenderal Pendidikan Anak Usia Dini Pendidikan dasar dan Pendidikan Menengah, dalam rangka memberikan arahan dan informasi.

f. Secara internal, untuk menjamin akurasi informasi dilakukan oleh tenaga di Sistem Informasi (SI).

g. Memfasilitasi tenaga Widyaprada untuk belajar mandiri dan berkonsultasi dengan instansi Pembina di pusat agar mendapatkan gambaran dan arahan tentang tugas dan fungsi.

\section{Pembahasan}

Perencanaan pengelolaan sumber daya manusia Widyaprada di LPMP Kalimantan Barat sudah dilaksanakan sesuai dengan 
peraturan yang berlaku, dimana pihak LPMP Kalimantan Barat menyusun rencana program kegiatan dan jadwal, rencana anggaran dan sarana prasarana pendukung. Di samping itu pula diberi kesempatan untuk mengajukan usulan kebutuhan personil atau pegawai, namun khusus untuk tenaga fungsional Widyaprada belum pernah diusulkan. Mengenai perekrutan, seleksi, penerimaan, pengujian dan pengambilan keputusan sepenuhnya adalah wewenang instansi pusat yaitu Kementerian Pendidikan, Kebudayaan, Riset dan Teknologi. Apabila sudah ada kebijakan dari pusat mengenai pengusulan kebutuhan tenaga fungsional Widyaprada dan LPMP Kalimantan Barat sudah menjadi Balai Besar Peningkatan Mutu Pendidikan (BBPMP) maka kesempatan tersebut diharapkan dapat dimanfaatkan sebaikbaiknya mengingat Widyaprada yang bertugas di LPMP Kalimantan Barat saat ini beberapa tahun ke depan akan memasuki batas usia pensiun karena usia widyaprada yang ada sekarang antara 50 sampai dengan 60 tahun.

Pelaksanaan pengelolaan sumber daya manusia Widyaprada di LPMP Kalimantan Barat sudah berjalan dengan baik, mengikuti ketentuan yang berlaku. Setiap pegawai yang baru bertugas akan diperkenalkan dengan pegawai-pegawai yang ada, diperkenalkan pula dengan kondisi lingkungan kerja, dijelaskan mengenai tugas dan fungsi LPMP dan akan diberi arahan singkat mengenai spesifikasi pekerjaan yang akan dilakukan dan berkaitan dengan rencana program kerja yang telah disusun. Mengenai kompensasi, setiap tenaga fungsional Widyaprada berhak menerima gaji sebagaimana peraturan yang berlaku dan berhak menerima tunjangan kinerja sebagaimana yang tercantum di dalam SK Pengangkatan sebagai Widyaprada.

Selain itu, setiap pejabat fungsional Widyaprada apabila melaksanakan tugas di lapangan berhak menerima kompensasi lainnya seperti uang transport, uang harian (uang saku dan uang makan) dan uang penginapan (akomodasi) sebagaimana yang diatur dalam Peraturan Menteri Keuangan No. 119/PMK.02/2020 tentang Standar Biaya Masukan Tahun 2021. Namun, tidak berhak menerimanya apabila kegiatan dilaksanakan oleh LPMP Kalimantan Barat dan bertempat di Kampus LPMP Kalimantan Barat. Mengenai pembinaan perilaku maka akan dilihat dari sikap terhadap atasan dan rekan sejawat, sikap terhadap pekerjaan dan loyalitas dalam bekerja. Sedangkan untuk kedisiplinan akan dilihat dari kehadiran, ketepatan waktu bekerja, ketepatan waktu menyelesaikan pekerjaan dan kesiapan dalam menjalankan tugas yang diamanahkan. Adapun kendala yang dihadapi dalam pelaksanaan pengelolaan sumber daya manusia di LPMP Kalimantan Barat pada saat ini adalah karena belum adanya kegiatan di lapangan yang benar-benar dapat menjadi tolak ukur kinerja kerja tenaga fungsional Widyaprada akibat dari adanya pandemi COVID-19 yang berlangsung sejak tahun lalu. Bahkan tenaga fungsional Widyaprada pun diangkat di masa pandemi, yaitu pada bulan Juli 2020.

Evaluasi pengelolaan sumber daya manusia Widyaprada dilakukan dan diterima pada setiap awal tahun (evaluasi tahun 2020 dilakukan awal tahun 2021) dalam bentuk Sasaran Kinerja Pegawai. Evaluasi pengelolaan sumber daya manusia Widyaprada dilakukan oleh atasan langsung yaitu Kepala LPMP Kalimantan Barat dan hasil evaluasi akan dibahas bersama-sama dengan Kasubbag Umum dan tenaga fungsional Widyaprada. Adapun yang menjadi dasar pengambilan keputusan untuk menyikapi hasil evaluasi adalah analisis evaluasi kinerja dan pencapaian sasaran kinerja secara umum, bukan perseorangan, sehingga implikasi pembahasan hasil evaluasi juga ditujukan untuk seluruh tenaga fungsional Widyaprada dan seluruh pegawai di LPMP Kalimantan Barat.

Hasil evaluasi pengelolaan sumber daya manusia Widyaprada di LPMP Kalimantan Barat dimanfaatkan untuk menganalisis dan menentukan program pengembangan yang diperlukan atau dibutuhkan oleh Widyaprada 
yang akan dimasukkan saat penyusunan program pada tahun anggaran berikutnya. Kemudian dijadikan pula sebagai dasar untuk menentukan apa yang dibutuhkan Widyaprada secara keseluruhan, seperti kemungkinan untuk mengikuti pendidikan dan pelatihan atau diperlukan pendekatan-pendekatan lainnya. Selanjutnya, dijadikan sebagai dasar untuk penyusunan program yang lebih mengarah pada tugas-tugas Widyaprada seperti pendampingan atau pembinaan pada satuan pendidikan. Paling utama adalah hasil evaluasi dijadikan dasar untuk menyusun rencana program kerja pada tahun berikutnya.

Berdasarkan data hasil penelitian, maka ditemukan hambatan-hambatan yang dihadapi dalam pengelolaan sumber daya manusia Widyaprada di LPMP Kalimantan Barat, yaitu:

1. Perubahan aturan dari Kementerian Pendidikan dan Kebudayaan yang terjadi pada saat program kerja dan aktivitas rutin instansi sedang berjalan menyebabkan instansi harus melakukan penyesuaian terhadap program dan alokasi anggaran. Ini menyebabkan adanya sasaran kerja di beberapa aspek yang harus dikurangi, namun ada pula yang harus ditambah untuk beberapa aspek lainnya.

2. Tenaga fungsional Widyaprada harus menganalisis sendiri dan menyesuaikan dengan kondisi, karena LPMP Kalimantan Barat sedang berada pada masa transisi untuk menjadi Balai Besar Peningkatan Mutu Pendidikan, sehingga program-program yang dilaksanakan adalah program-program transisi. Belum ada arahan baik berupa bimbingan maupun petunjuk teknis tentang tugas dan fungsi dari Direktorat Jenderal Pendidikan Anak Usia Dini, Pendidikan Dasar dan Pendidikan Menengah untuk Widyaprada.

3. Perubahan kebijakan sebagai langkah untuk menyesuaikan diri terhadap kondisi menyebabkan terjadinya perubahan format dan program kegiatan. Seperti sekarang di masa pandemi, sulit bagi LPMP Kalimantan Barat dan Widyaprada untuk melakukan kegiatan tatap muka.
Selain itu, sulit juga bagi Widyaprada untuk melakukan monitoring dan pendampingan ke satuan-satuan pendidikan.

Berdasarkan data hasil penelitian, diketahui bahwa terdapat beberapa upaya yang dilakukan LPMP Kalimantan Barat untuk mengatasi hambatan dalam pengelolaan sumber daya manusia Widyaprada, yaitu:

1. Dari awal sudah diantisipasi dengan cara membentuk tim yang solid dan mampu untuk bekerjasama, sehingga dapat dengan cepat dan tepat menyikapi setiap perubahan dalam organisasi yang berpengaruh terhadap pelaksanaan program kerja.

2. Selalu tanggap dan terus melakukan koordinasi apabila terjadi suatu perubahan agar dapat dengan cepat menyesuaikan diri.

3. Terus menerus melakukan analisis sumber daya manusia dengan tetap berpedoman pada panduan dan arahan dari Instansi pusat (melalui kegiatan bimbingan teknis yang diselenggarkan oleh instansi pusat).

4. Selalu memenuhi undangan dari instansi pusat untuk kegiatan koordinasi agar dapat menyampaikan hasil analisis kebutuhan organisasi sebagaimana yang disusun oleh Kasubbag Umum dan bagian tata laksana kepegawaian.

5. Seminggu sekali dilakukan pertemuan secara daring oleh Unit utama untuk Kepala-Kepala LPMP se-Indonesia dipimpin langsung oleh Sekretaris Direktorat Jenderal Pendidikan Anak Usia Dini, Pendidikan Dasar dan Pendidikan Menengah dalam rangka memberikan arahan dan informasi.

6. Secara internal, untuk menjamin akurasi informasi dilakukan oleh tenaga di Sistem Informasi (SI). Dan untuk pejabat fungsional Widyaprada difasilitasi untuk dapat berkonsultasi ke instansi pusat di Jakarta, agar mendapatkan gambaran dan arahan tentang tugas dan fungsinya.

\section{SIMPULAN DAN SARAN}




\section{Simpulan}

Berdasarkan hasil penelitian tentang pengelolaan sumber daya manusia Widyaprada di LPMP Kalimantan Barat, maka dapat disimpulkan sebagai berikut:

\section{Perencanaan Sumber Daya Manusia Widyaprada}

Proses perencanaan sumber daya manusia Widyaprada sudah berjalan dengan baik sesuai dengan peraturan yang berlaku. Sistem penyaringan atau seleksi untuk dapat menjadi pejabat fungsional widyaprada dilakukan oleh Kementerian Pendidikan, Kebudayaan, Riset dan Teknologi secara nasional, dan LPMP Kalimantan Barat tinggal menerima hasilnya. Perencanaan mengenai pengadaan sumber daya manusia Widyaprada belum pernah diusulkan oleh LPMP Kalimantan Barat, karena masih menunggu kebijakan dan peraturan dari Kementerian Pendidikan, Kebudayaan, Riset dan Teknologi. Seluruh tenaga fungsional Widyaprada yang ada saat ini ditentukan oleh instansi Kementerian Pendidikan, Kebudayaan, Riset dan Teknologi melalui proses inpasing.

\section{Pelaksanaan Pengelolaan Sumber Daya Manusia Widyaprada}

Pelaksanaan sumber daya manusia Widyaprada sudah berjalan dengan baik. Secara umum, setiap pegawai yang baru bertugas akan diperkenalkan dengan pegawaipegawai lainnya, diperkenalkan juga dengan kondisi lingkungan kerja dan diinformasikan mengenai tugas dan fungsi LPMP Kalimantan Barat. Pejabat fungsional Widyaprada berhak menerima gaji sesuai dengan peraturan yang berlaku, berhak menerima tunjangan kinerja sesuai dengan peraturan, berhak menerima kompensasi lainnya seperti uang harian, uang transport dan uang penginapan (akomodasi) sesuai dengan peraturan yang berlaku

\section{Evaluasi Pengelolaan Sumber Daya}

\section{Manusia Widyaprada}

Evaluasi pengelolaan sumber daya manusia Widyaprada dilakukan di awal tahun dalam bentuk penilaian Sasaran Kinerja Pegawai. Evaluasi dilakukan oleh atasan langsung dari tenaga fungsional Widyaprada, yaitu Kepala LPMP Kalimantan Barat. Hasil penilaian digunakan untuk menganalisis dan menentukan program pengembangan yang dibutuhkan oleh Widyaprada yang akan dimasukkan saat penyusunan program pada tahun anggaran berikutnya. Hasil Penilaian dijadikan pula sebagai dasar untuk menentukan apa yang dibutuhkan Widyaprada secara keseluruhan, seperti kemungkinan untuk mengikuti pendidikan dan pelatihan atau diperlukan pendekatan-pendekatan lainnya. Selanjutnya, hasil evaluasi juga dijadikan sebagai dasar untuk penyusunan program yang lebih mengarah pada tugas dan fungsi Widyaprada seperti pembimbingan dan pendampingan pada satuan pendidikan. Hasil evaluasi dijadikan dasar untuk menyusun rencana program kerja pada tahun berikutnya.

4. Hambatan-hambatan yang Dihadapi dalam Pengelolaan Sumber Daya Manusia Widyaprada

Hambatan-hambatan yang dihadapi dalam pengelolaan sumber daya manusia Widyaprada di LPMP Kalimantan Barat adalah program dan anggaran menjadi terhambat apabila terjadi perubahan aturan secara mendadak. Kemudian, karena berada pada masa transisi untuk menjadi Balai Besar Peningkatan Mutu Pendidikan, maka program-program yang dilaksanakan adalah program-program transisi, sehingga Widyaprada harus menganalisis sendiri dan menyesuaikannya dengan kondisi wilayah kerja. Selanjutnya adalah perubahan kebijakan yang terjadi di saat proses kerja sedang berjalan akan berpengaruh pada pelaksanaan program kegiatan.

\section{Upaya yang Dilakukan untuk Mengatasi Hambatan dalam Pengelolaan Sumber Daya Manusia Widyaprada \\ Upaya yang dilakukan LPMP} Kalimantan Barat untuk mengatasi hambatan dalam pengelolaan sumber daya manusia Widyaprada adalah menciptakan tim yang solid dan dapat bekerjasama dengan baik untuk menyikapi perubahan yang mungkin terjadi secara mendadak, melakukan penyesuaian diri untuk menyikapi perubahan lingkungan, melakukan analisis SDM berdasarkan panduan dan arahan dari pusat 
(melalui kegiatan bimbingan teknis yang diselenggaran oleh instansi pusat), menganalisis kebutuhan organisasi yang disusun oleh Kasubbag Umum dan bagian tata laksana kepegawaian, mengikuti rapat koordinasi secara daring oleh Unit eselon I untuk Kepala-Kepala LPMP se-Indonesia yang dipimpin langsung oleh Sekretaris Direktorat Jenderal Pendidikan Anak Usia Dini, Pendidikan Dasar dan Pendidikan Menengah dalam rangka memberikan arahan dan informasi. Kemudian, untuk menjamin akurasi informasi dilakukan oleh tenaga di Sistem Informasi (SI) dan memfasilitasi tenaga Widyaprada untuk belajar dan berkonsultasi ke instansi pusat agar mendapatkan gambaran dan arahan tentang tugas dan fungsinya.

\section{Saran}

Berdasarkan uraian di atas, maka demi kemajuan dan ketercapaian tujuan pengelolaan sumber daya manusia Widyaprada di Lembaga Penjaminan Mutu Pendidikan Kalimantan Barat, maka peneliti menyampaikan beberapa saran dan gagasan yang diharapkan dapat bermanfaat bagi keberhasilan pengelolaan sumber daya manusia Widyaprada. Adapun saran dan gagasan tersebut adalah sebagai berikut:

1. Untuk Direktorat Jenderal Pendidikan Anak Usia Dini, Pendidikan Dasar, dan Pendidikan Menengah

a. Menyiapkan petunjuk teknis mengenai tata cara pengusulan kebutuhan tenaga fungsional Widyaprada bagi seluruh LPMP di Indonesia. Mengingat beberapa tenaga fungsional Widyaprada mulai memasuki batas usia pensiun, sehingga membutuhkan adanya pergantian atau penambahan pejabat fungsional Widyaprada.

b. Melakukan komunikasi dan memberikan arahan secara intensif tidak hanya dengan Kepala LPMP, namun juga dengan pejabat fungsional Widyaprada.

c. Bekerjasama dengan Dinas Pendidikan untuk mendapatkan informasi mengenai kebutuhankebutuhan apa yang diperlukan oleh satuan pendidikan dalam upaya penjaminan mutu pendidikan.

2. Untuk Kepala LPMP Kalimantan Barat

a. Secara kontinu memberikan pengarahan dan melakukan pertemuan dengan pejabat fungsional Widyaprada dalam rangka koordinasi program, tugas dan fungsi Lembaga serta tugas dan fungsi pejabat fungsional widyaprada.

b. Menjajaki kemungkinan untuk bekerjasama dengan Dinas Pendidikan setempat dalam rangka pelaksanaan kegiatan penjaminan mutu pendidikan yang dapat mengakomodir peran, tugas dan fungsi Widyaprada.

3. Untuk Kasubbag Umum

a. Dapat membuat format data khusus tentang kondisi Widyaprada, sehingga dapat diketahui masa kerja dan batas usia pensiun pajabat fungsional Widyaprada.

b. Secara kontinu berkoordinasi dengan Widyaprada mengenai program kerja yang telah dilaksanakan dan yang akan dilaksanakan, dan mencari informasi tentang kegiatan dari pihak luar yang diikuti oleh Widyaprada baik sebagai peserta maupun sebagai narasumber.

4. Untuk tenaga fungsional Widyaprada

a. Aktif berkonsultasi dan berkoordinasi mengenai program kerja dengan Kasubbag Umum, Kepala LPMP dan jika memungkinkan dengan Unit Eselon I di pusat.

b. Menyampaikan gagasan-gagasan yang inovatif kepada Kepala LPMP Kalimantan Barat dalam rangka pelaksanakan tugas dan fungsi Widyaprada yang berkaitan dengan penjaminan mutu pendidikan.

5. Untuk calon peneliti selanjutnya

a. Mengadakan penelitian mengenai pelaksanaan tugas pejabat fungsional Widyaprada apabila LPMP Kalimantan Barat, sudah menjadi 
Balai Besar Peningkatan Mutu Pendidikan (BBPMP).

b. Mengadakan penelitian tentang kegiatan penjaminan mutu pendidikan pada satuan pendidikan di salah satu Kabupaten/Kota di Kalimantan Barat.

\section{DAFTAR RUJUKAN}

Emzir (2009). Metode Penelitian Pendidikan: Kuantitatif dan Kualitatif. Jakarta: Rajawali Press.

Garaika (2020), Manajemen Sumber Daya Manusia. Yogyakarta: Zahir Publishing.

Lpmpkalbar.id (2020, 12 November), Visi, Misi dan Strategi, Diakses pada 12 November 2020, dari https://www.lpmpkalbar.id /index.php/selayang-pandang/visi-danmisi.

Priyono d., \& Marnis (2008), Manajemen Sumber Daya Manusia. Sidoarjo: Zifatama Publisher.

Torres-Coronas, Teresa d., \& Arias-Olivia, Mario (2005), e-Human Resources Management: Managing Knowledge People. London: Idea Group Publishing.

Vanderstoep, Scott W d., \& Johnston, Deirdre D (2009), Research Methods for Everyday Life: Blending Qualitative and Quantitative Approaches. San Fransisco: Josey-Bass a Willey Imprint.

Sugiyono (2018). Metode Penelitian Kualitatif: Untuk Penelitian yang Bersifat Eksploratif, Enterpretif, Interaktif dan Konstruktif. Bandung: Alfabeta. 